\title{
Ottawa wants your views on drug transparency
}

$\mathrm{U}$ ntil May 25, Canadians who are concerned about the way the federal government monitors and releases clinical trial data and other prescription and nonprescription drug information can make their views known to Health Canada.

The federal department has created an online survey asking what information people want about drugs, how it should be available and who should provide it. The survey is open to anyone.

Health Canada will use the data as it writes regulations on how it delivers information about the safety of drugs, vaccines, medical devices and other therapeutic products. That information could potentially involve not only details included in the registration of clinical trials but also the release of summary results and even raw, anonymized data, says Matthew Herder, an assistant professor in the faculties of medicine and law at Dalhousie University in Halifax who has studied the legislation and testified before the parliamentary Health committee.

Herder is urging clinicians and researchers to participate in the consultations, particularly as pharmaceutical companies are sure to do so. He hopes Health Canada won't be unduly swayed if the survey is weighted toward industry views on what clinical trial data to release.

"It cannot be used to trump a mountain of literature about the importance of registering clinical trials, and making anonymized patient data available as well," Herder told $C M A J$ in an interview.

The consultations flow from the Protecting Canadians from Unsafe Drugs Act, which received royal assent in November 2014. Also known as Vanessa's Law, the legislation amended the Food and Drugs Act to give the health minister greater regulatory power over therapeutic products, including the ability to recall drugs if there are safety concerns about them.

In addition to the survey, Health Canada has released a guide outlining

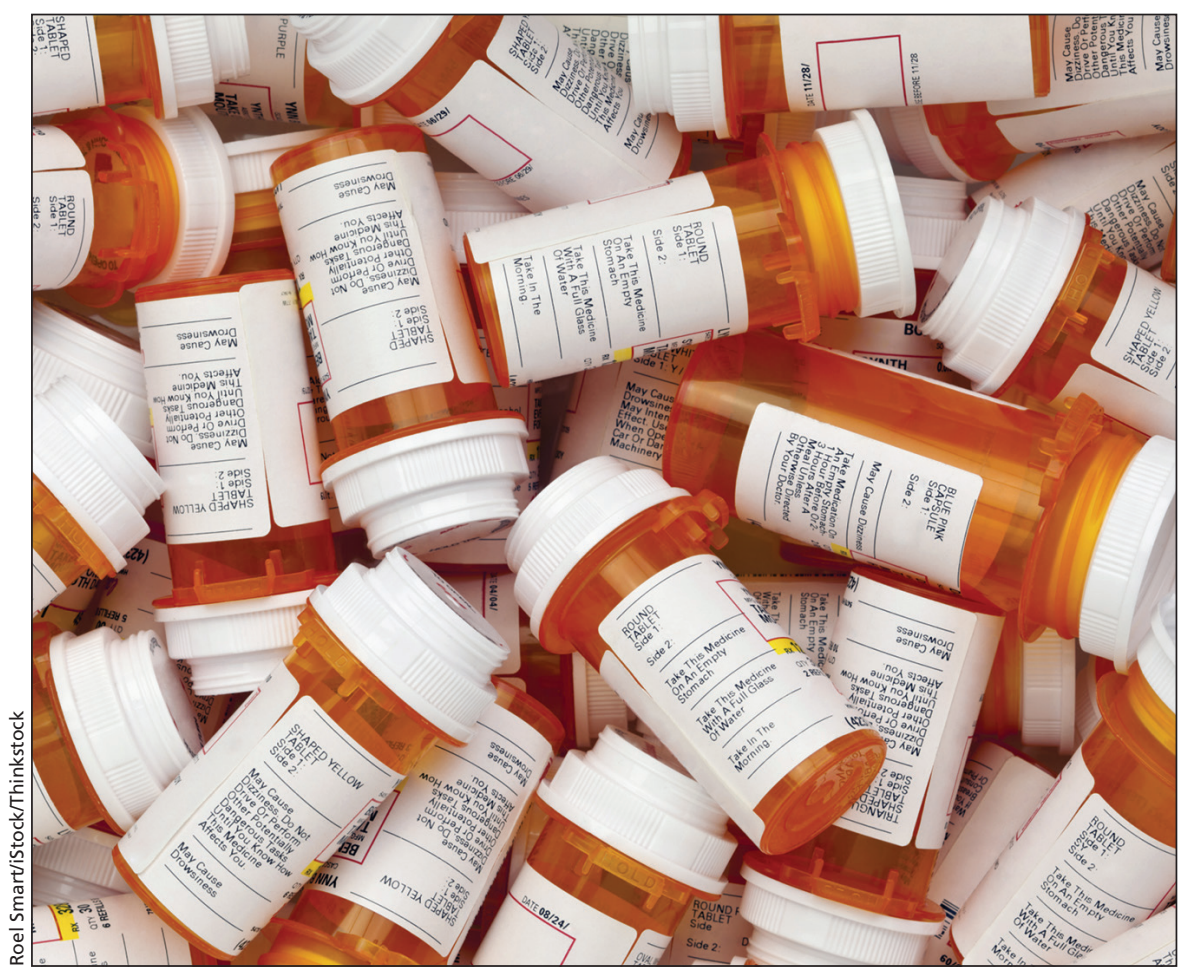

Before fully implementing a law on releasing clinical trial data and other drug information, the federal government is asking Canadians what they want to know.

when the minister may exercise her authority to require pharmaceutical companies to disclose information about a drug, and under what circumstances she can recall a drug or order changes to its official label. Until June 8, the department is also seeking comments from interested parties on the Guide to New Authorities, a draft of which is already in use.

The guide makes clear recall "[o] rders will be issued only when necessary" after a company or individual has been notified of any risk of injury and has the opportunity to take voluntary action. The regulations give the minister or Health Canada officials the power to seek an injunction if they anticipate noncompliance, but the company or individual named in that injunction would have 48 hours' notice of any government action unless "notice would not be in the public interest."

The minister's new power includes the authority to compel a company or individual to provide Health Canada with whatever information it needs to assess whether a drug poses a health risk. That information could include pre- or postmarket trial data, including adverse drug reaction reporting.

As long as she has "reasonable grounds" to believe a product poses a serious risk of injury, the minister can now also disclose confidential business information about a drug or device to another government official, an advisor, or to a public health or safety official without notifying the company or individual marketing the product.

The guide contains a loophole, however. Cabinet - not health officials - can decide what constitutes "confidential business information" and will use its regulation-making power under the new law to authorize disclosure. In addition, the decision to disclose must comply with Canada's treaty obligations regarding new drugs, as outlined in the North Ameri- 
can Free Trade Agreement and other international treaties that govern the pharmaceutical sector and multinational drug companies.

The wording of the guide seems to indicate that trade agreements could be used to water down the transparency provisions the law is intended to secure, says Herder.
Until Health Canada has completed these consultations and issued the regulations that will accompany the legislation, it's still unclear whether the department will interpret data derived from patients participating in clinical trials as confidential business information, and whether, for example, it will decide that researchers or doctors prescribing partic- ular drugs will fall into the categories of people to whom they can disclose this information, Herder says.

"A lot of it still hangs on the wording of some regulations that we still don't have." - Laura Eggertson, Ottawa, Ont.

CMAJ 2015. DOI:10.1503/cmaj.109-5041 